Minireview

\title{
Functional genomic and epidemiological studies reveal novel genes regulating cholesterol metabolism
}

\author{
Kris Richardson and Jose M Ordovas
}

\begin{abstract}
Address: Nutrition and Genomics Laboratory, Lipid Metabolism Laboratory, Jean Mayer-United States Department of Agriculture Human Nutrition Research Center on Aging, Tufts University, 711 Washington Street, Boston, MA 02111, USA.

Correspondence: Kris Richardson. Email: kris.richardson@tufts.edu
\end{abstract}

\begin{abstract}
Elevated plasma cholesterol is a heritable trait and a risk factor for the development of cardiovascular disease. Although several major biochemical pathways regulating cholesterol metabolism have been identified, questions regarding the details of this regulation remain. In fact, common genetic polymorphisms in candidate genes explain only 5 to $7 \%$ of variation in high- and low-density lipoprotein cholesterol levels between individuals. This suggests that many of the factors influencing cholesterol metabolism, and potentially the etiology of cardiovascular disease, are unknown. Here, we review recent functional genomic research that, combined with results from genomewide association studies, provides a powerful tool to identify novel candidate genes relevant to cholesterol metabolism.
\end{abstract}

\section{The role of cholesterol in the etiology of cardiovascular disease}

Cholesterol is an integral component of lipid membranes in eukaryotic cells that is required for maintaining membrane fluidity and facilitating the trafficking and signaling of membrane-associated proteins. Cholesterol is also a necessary precursor for important metabolites, such as steroid hormones, bile salts and oxysterols. Several pathways coordinate cholesterol homeostasis in the body [1]. Briefly, in the first pathway, cells acquire cholesterol, primarily through the binding of circulating cholesterolrich low-density lipoprotein (LDL) particles to cellular lipoprotein receptors. The receptor-ligand complex is subsequently absorbed into the cell through clathrinmediated endocytosis, and cholesterol is then used by a variety of downstream biochemical pathways. In the second pathway, cholesterol is synthesized when intracellular levels are low, through activation of the SCAP/ SREBP signaling cascade. SREBP (sterol regulatory element binding protein) is a transcription factor that regulates expression of numerous cholesterol synthesizing genes, and SCAP (SREBP cleavage activating protein) regulates its activity. Finally, a reverse cholesterol transport pathway is activated when the cell accumulates excess cholesterol, which must then be transported to the liver for excretion into the bile. In this third pathway, circulating high-density lipoprotein (HDL) acts as the primary acceptor of cholesterol from non-liver cells.

Together, these pathways involve a network of many transcription factors, binding proteins, enzymes and receptors. Alterations in these pathways that lead to elevated plasma cholesterol levels correlate strongly with increased risk of cardiovascular disease (CVD) [2]. For example, familial hypercholesterolemia, which is caused by mutations in the low density lipoprotein receptor $(L D L R)$ gene, leads to a reduced number of functional LDL receptors and results in the severe elevation of plasma LDL cholesterol levels [3].

\section{The gaps in our understanding of cholesterol metabolism}

Given the importance of cholesterol homeostasis in the prevention of CVD, it is crucial to understand the many genetic and biochemical factors regulating these pathways. Although most monogenic disorders associated with hypercholesterolemia have been identified, our understanding of common genetic factors contributing to elevated plasma cholesterol remains limited [4]. The heritability of human plasma cholesterol levels is estimated to be in the range 50 to $70 \%$. Furthermore, common polymorphisms that reproducibly modulate plasma cholesterol levels account for only a small portion of this genetic contribution. A series of genome-wide association studies (GWASs) have been published in the past year [5-7] that identified novel variants in candidate loci that modulate plasma cholesterol levels. These studies [5-7] benefited from large sample sizes spanning multiple cohorts, allowing investigators to achieve power great enough to detect variants showing modest effects. In addition, a study by Sabatti et al. [8] demonstrated that some of these associations may be further modulated by interactions between

CVD, cardiovascular disease; ETV5, ETS variant 5; GWAS, genome-wide association study; HDL, high density lipoprotein; LDL, low density lipoprotein; NPC1, Niemann-Pick disease type C1; SCAP, SREBP cleavage activating protein; SREBP, sterol regulatory element binding protein; TMEM97, transmembrane protein 97. 
variants and environmental factors. Evidence for the environmental modification of trait variation is accumulating, and it is reasoned this information will help clarify the discrepancies observed between contradicting association studies $[8,9]$. However, even with this most recent progress, the known common genetic factors linked to cholesterol explain 5 to $7 \%$ of heritability [10].

In addition to our limited knowledge of genetic factors, we lack many of the details regarding the biochemical pathways regulating cholesterol homeostasis, such as the identity of proteins involved in processes of cellular cholesterol transport and trafficking, sterol-mediated gene expression and protein-protein and protein-cholesterol interactions [1,11]. Although a few of the loci associated with plasma cholesterol levels in the GWASs [5-7] have known functions, many of the variants showing association lack a functional explanation. Furthermore, to better treat and prevent CVD we must implement comprehensive integrative functional genomic and proteomic methods that offer complementary and detailed information on the identity and function of additional factors that contribute to the regulation of plasma cholesterol levels.

\section{A promising new strategy for candidate gene identification}

A recent publication by Bartz et al. [12] undertook this exact task by systematically identifying regulators of cholesterol homeostasis using a functional genomics strategy. By comparing the genome-wide expression profiles of steroldepleted and control HeLa cells, the authors [12] were able to identify 308 genes that showed statistically significant differences in expression between the two conditions. Of these genes, 100 were subsequently used as candidates for two cell-based RNA interference (RNAi) screens investigating their potential role in regulating total cellular cholesterol levels and uptake of cellular cholesterol. This strategy identified a number of genes significantly modulating at least one of these processes. Included in this list were known regulators of cholesterol metabolism, such as $S C A P$ and $L D L R$, in addition to 20 novel genes considered functionally relevant [12].

To validate their approach, the authors [12] chose to further investigate the function of one candidate, transmembrane protein 97 (TMEM97). Expression of TMEM97 was upregulated in sterol-depleted cells, and RNAi knockdown reduced cellular uptake and total cellular levels of cholesterol. Furthermore, analysis of the genomic sequence of TMEM97 identified a putative SREBP binding motif in its promoter and showed that its transcriptional activity was eliminated in sterol-depleted cells lacking SREBP-2. Most interestingly, the authors demonstrated that TMEM97 localizes to the lysosomal and plasma membrane compartments and interacts with the endosomal/ lysosomal transporter protein NPC1 (Niemann-Pick disease, type $\mathrm{C} 1$ ) following sterol depletion. These studies led them to postulate that, in low sterol conditions, TMEM97 is recruited to the lysosome, where it interacts with NPC1 to induce alterations in cholesterol transport [12].

This is the first example [12] in which an integrative functional genomics approach has been used to uncover factors participating in the regulation of cholesterol, and this is just the tip of the iceberg, considering that there are at least a dozen more candidates from this study that have strong supporting evidence for involvement in these processes.

\section{How these findings will affect the treatment of CVD}

Finding new and more powerful methods for the identification of genetic factors, and their contribution to the biochemical pathways regulating cholesterol metabolism, is essential for the successful treatment and prevention of CVD. With each new factor identified, there arises a potential new target for therapy.

The use of functional genomic strategies should provide immediate identification of candidate loci involved in cholesterol metabolism, thereby expanding the regions of genomic coverage relevant to lipid metabolism for investigators performing GWASs. For example, a variant in ETS variant 5 (ETV5), a gene identified by Bartz et al. [12] as a regulator of cholesterol uptake, has shown an association with modulation of obesity-related phenotypes in a recent GWAS [13]. Further in vitro studies investigating its localization and protein-protein interactions, similar to those performed with TMEM97, may help place ETV 5 in a known or novel pathway(s) regulating cholesterol metabolism. Moreover, potential associations of variants in the ETV 5 locus, and other genes identified by Bartz et al. [12], with lipid phenotypes remain to be investigated.

These new approaches for identification of gene candidates, and their functions, provide us with exciting expectations for the study of cholesterol metabolism. These techniques will provide us with candidates for functional and epidemiological studies aimed at identifying their contribution to the processes of cholesterol regulation and the effect of genetic variation on these processes. The use of these integrative strategies will contribute to a better understanding of the relationship between our genetics, environment and potential for disease.

\section{Authors' contributions}

KR and JMO both contributed to the conception, design and drafting of the manuscript. JMO has given final approval of this version to be published.

\section{Competing interests}

The authors declare that they have no competing interests. 


\section{Acknowledgements}

This work was supported by NIH grants HL72524, HL54776 and DK075030 and by contracts 53-K06-5-10 and 58-1950-9-001 from the US Department of Agriculture Research Service.

\section{References}

1. Chang TY, Chang CC, Ohgami N, Yamauchi Y: Cholesterol sensing, trafficking, and esterification. Annu Rev Cell Dev Biol 2006, 22:129-157.

2. Third report of the National Cholesterol Education Program (NCEP) Expert Panel on Detection, Evaluation, and Treatment of High Blood Cholesterol in Adults (Adult Treatment Panel III) final report. Circulation 2002, 106:3143-3421.

3. Austin MA, Hutter CM, Zimmern RL, Humphries SE: Genetic causes of monogenic heterozygous familial hypercholesterolemia: a HuGE prevalence review. Am J Epidemiol 2004, 160:407-420.

4. Pullinger CR, Kane JP, Malloy MJ: Primary hypercholesterolemia: genetic causes and treatment of five monogenic disorders. Expert Rev Cardiovasc Ther 2003, 1:107-119.

5. Aulchenko YS, Ripatti S, Lindqvist I, Boomsma D, Heid IM, Pramstaller PP, Penninx BW, Janssens AC, Wilson JF, Spector T, Martin NG, Pedersen NL, Kyvik KO, Kaprio J, Hofman A, Freimer NB, Jarvelin MR, Gyllensten U, Campbell H, Rudan I, Johansson A, Marroni F, Hayward C, Vitart V, Jonasson I, Pattaro C, Wright A, Hastie N, Pichler I, Hicks AA, et al.: Loci influencing lipid levels and coronary heart disease risk in 16 European population cohorts. Nat Genet 2009, 41:47-55.

6. Kathiresan S, Melander O, Guiducci C, Surti A, Burtt NP, Rieder MJ, Cooper GM, Roos C, Voight BF, Havulinna AS, Wahlstrand B, Hedner T, Corella D, Tai ES, Ordovas JM, Berglund G, Vartiainen E, Jousilahti P, Hedblad B, Taskinen MR, NewtonCheh C, Salomaa V, Peltonen L, Groop L, Altshuler DM, OrhoMelander M: Six new loci associated with blood low-density lipoprotein cholesterol, high-density lipoprotein cholesterol or triglycerides in humans. Nat Genet 2008, 40:189-197.

7. Kathiresan S, Willer CJ, Peloso GM, Demissie S, Musunuru K, Schadt EE, Kaplan L, Bennett D, Li Y, Tanaka T, Voight BF,
Bonnycastle LL, Jackson AU, Crawford G, Surti A, Guiducci C Burtt NP, Parish S, Clarke R, Zelenika D, Kubalanza KA Morken MA, Scott LJ, Stringham HM, Galan P, Swift AJ, Kuusisto J, Bergman RN, Sundvall J, Laakso $M$, et al.: Common variants at $\mathbf{3 0}$ loci contribute to polygenic dyslipidemia. Nat Genet 2009, 41:56-65.

8. Sabatti C, Service SK, Hartikainen AL, Pouta A, Ripatti S, Brodsky J, Jones CG, Zaitlen NA, Varilo T, Kaakinen M, Sovio U, Ruokonen A, Laitinen J, Jakkula E, Coin L, Hoggart C, Collins A, Turunen H, Gabriel S, Elliot P, McCarthy MI, Daly MJ, Jarvelin MR, Freimer NB, Peltonen L: Genome-wide association analysis of metabolic traits in a birth cohort from a founder population. Nat Genet 2009, 41:35-46.

9. Corella D, Ordovas JM: Single nucleotide polymorphisms that influence lipid metabolism: interaction with dietary factors. Annu Rev Nutr 2005, 25:341-390.

10. Lusis AJ, Pajukanta $P$ : A treasure trove for lipoprotein biology. Nat Genet 2008, 40:129-130.

11. Ikonen E: Cellular cholesterol trafficking and compartmentalization. Nat Rev Mol Cell Biol 2008, 9:125-138.

12. Bartz F, Kern L, Erz D, Zhu M, Gilbert D, Meinhof T, Wirkner U Erfle H, Muckenthaler M, Pepperkok R, Runz H: Identification of cholesterol-regulating genes by targeted RNAi screening. Cell Metab 2009, 10:63-75.

13. Thorleifsson G, Walters GB, Gudbjartsson DF, Steinthorsdottir V, Sulem P, Helgadottir A, Styrkarsdottir U, Gretarsdottir S, Thorlacius ' $\mathrm{S}$, Jonsdottir I, Jonsdottir T, Olafsdottir EJ, Olafsdottir $\mathrm{GH}$, Jonsson $\mathrm{T}$, Jonsson $\mathrm{F}$, Borch-Johnsen $\mathrm{K}$ Hansen T, Andersen G, Jorgensen T, Lauritzen T, Aben KK, Verbeek AL, Roeleveld N, Kampman E, Yanek LR, Becker LC, Tryggvadottir L, Rafnar T, Becker DM, Gulcher J, et al.: Genome-wide association yields new sequence variants at seven loci that associate with measures of obesity. Nat Genet 2009, 41:18-24.

Published: 27 October 2009

doi:10.1186/gm96

(C) 2009 BioMed Central Ltd 